\title{
Analisis Struktur Pasar Sayuran di Desa Kanreapia Kecamatan Tinggimoncong Kabupaten Gowa Provinsi Sulawesi Selatan
}

\author{
An Analysis of the Structure of the Vegetable Market in Kanreapia Village Tinggimoncong \\ District Gowa Regency South Sulawesi Province
}

\author{
Aylee Christine Alamsyah Sheyoputri ${ }^{*}$, Abri $^{2}$, \\ *Email: aylee.christine@universitasbosowa.ac.id \\ ${ }^{1}$ Program Studi Agribisnis Fakultas Pertanian Universitas Bosowa \\ ${ }^{2}$ Program Studi Agroteknologi Fakultas Pertanian Universitas Bosowa
}

\begin{abstract}
ABSTRAK
Potensi tanaman hortikultura khususnya sayuran yang ada di Kecamatan Tinggimoncong cukup besar bahkan beberapa jenis sayuran seperti kubis, petsai, wortel, bawang daun dan kentang, selain dipasarkan dalam wilayah kabupaten juga dipasarkan sampai ibukota propinsi bahkan di antar pulaukan ke Kalimantan namun demikian sistem pemasarannya masih bersifat tradisional yang berimplikasi pada pendapatan petani sebagai produsen tidak optimal. Penelitian ini bertujuan mengkaji stuktur pasar, saluran distribusi dan margin pemasaran produk usahatani sayur-sayuran yang berada di Desa Karenapia, Kecamatan Tinggimoncong, Kabupaten Gowa, Sulawesi Selatan. Dilaksanakan pada bulan April hingga Juni 2019, dengan menggunakan pendekatan deskriptif kuantitatif. Hasil penelitian menunjukan bahwa Struktur pasar sayuran yang terbentuk di desa Kanreapia mengarah pada pasar oligopsoni. Struktur pasar di tingkat kabupaten/kota, lebih memgarah pada pasar persaingan sempurna dan diferensiasi. petani sebagai produsen tidak memiliki sarana dan perlakuan pascapanen (standarisasi melalui grading), lemahnya informasi tentang pasar sehingga peranan petani dalam memanfaatkan peluang pasar sangat kecil, skala usaha yang relatif kecil dan usaha tani yang tidak didasarkan atas permintaan pasar, menyebabkan posisi tawar petani sangat lemah, hal ini memungkinkan kehadiran pedagang perantara yang kemudian lebih dominan dalam penentuan harga jual di tingkat petani. Bagian yang diterima petani dari harga yang dibayarkan konsumen untuk beberapa jenis sayuran, ratarata lebih kecil dibandingkan yang diterima oleh pedagang perantara sehingga sistem pemasaran yang terjadi dinilai kurang efisien bagi petani.
\end{abstract}

Kata Kunci: Pemasaran Sayuran, Margin Pemasaran, Efesiensi Pemasaran, Struktur Pasar, Petani

\begin{abstract}
The potential of horticultural crops, especially vegetables in the District of Tinggimoncong is quite considerable. Some types of vegetables such as cabbage, Chinese cabbage, carrots, leeks and potatoes, besides being marketed in the Regency Area, are also marketed to the provincial capital even interisland to Kalimantan. The marketing system, however, is still traditional, and that makes the income of the farmers as the producers is not optimal. This study aimed to examine the market structures, distribution channels and marketing margins of the vegetable farming products located in Kanreapia village Tinggimoncong District Gowa Regency South Sulawesi. Using a quantitative descriptive approach, it was carried out from April to June 2019. The results showed that the structure of the vegetable market formed in Kanreapia village led to an oligopsony market. The market structure at the Regency/Municipal level was more likely to lead to a perfect competition and differentiation market. Because the farmers as the producers did not have post-harvest treatment and facilities (standardization through grading), and were weak in terms of market information, the role of the farmers in taking the advantages of market opportunities was very small. The relatively small business scales and non-market-demand farming have caused the farmers' bargaining position very weak, allowing the presence of intermediary traders who in turn are more dominant in determining the selling prices at the farmer level. For several types of vegetables, the share received by the farmers from the
\end{abstract}


price paid by the consumers is, on average, smaller than that received by the intermediary traders. Hence, the marketing system that occurs is considered less efficient for farmers.

Keywords: Vegetable Marketing, Marketing Margin, Marketing Efficiency, Market Structure, Farmers.

This work is licensed under Creative Commons Attribution License 4.0 CC-BY International license

\section{A. PENDAHULUAN}

Sayuran merupakan komoditi pertanian berprospek cerah sebab permintaan terhadap komoditi ini cukup tinggi, mengingat sayuran termasuk pangan esensial karena mengandung zat gizi mikro berupa vitamin dan mineral. Andarwulan dan Faradilla (2012), mengemukakan bahwa senyawa fenolik dalam sayuran merupakan salah satu senyawa fitokimia yang paling banyak diteliti terkait manfaatnya sebagai anti oksidan. Peningkatan komsumsi sayuran dan buah dapat mencegah penyakit kronis dan mencegah penambahan berat badan, bahkan himbauan untuk mengkomsusi sayur dan buah dengan kandungan gizi seimbang pada masyarakat belahan dunia barat merupakan salah satu strategi utama dalam rangka mengurangi terjangkitnya penyakit kronis seperti obesitas, diabetes melitus tipe 2, hipertensi, jantung koroner, stroke dan lain-lain (Boeing et al,2012). Seiring dengan peningkatan jumlah penduduk dan kesadaran nilai gizi untuk hidup sehat menyebabkan permintaan sayuran di Indonesia terus meningkat. Konsumsi sayuran di Indonesia sebanyak $40 \mathrm{~kg} / \mathrm{kapita} / \mathrm{tahun}$, namun demikian angka konsumsi tersebut masih berada di bawah rekomendasi standar FAO yaitu $73 \mathrm{~kg} / \mathrm{kapita} / \mathrm{tahun}$. Salah satu upaya untuk meningkatkan konsumsi masyarakat terhadap sayuran maka diperlukan sistem pemasaran yang efesien dan efektif( Darian J.C.,2013)

Indonesia memiliki potensi yang besar bagi penyediaan produk sayuran, utamanya sayur-sayuran dataran tinggi, salah satunya adalah Kecamatan Tinggimoncong, Kabupaten Gowa, Propinsi Sulawesi Selatan yang merupakan pemasok utama kebutuhan sayuran di Kota Makassar dan kota-kota lainnya, namun tidak dapat dipungkiri bahwa pengelolaan usahatani di daerah tersebut belum optimal yang tercermin dari fluktuasi produksi, beragamnya kualitas serta merosotnya harga karena mekanisme fungsi pemasaran yang belum baik. Rusaknya produk pada kegiatan transportasi dan penyimpanan pada gilirannya akan menurunkan harga yang pada akhirnya berpengaruh pada pendapatan para pelaku pasar termasuk petani sebagai produsen. Dalam pemasaran komoditas pertanian, terdapat pelaku pasar yang terlibat secara langsung maupun tidak langsung, komoditas yang dipasarkan juga bervariasi kualitas, harga dan lembaga yang terlibat. Kompleksitas pemasaran tersebut 
memerlukan pendekatan secara terintegrasi sehingga dapat menguntungkan semua pihak, untuk itu pendekatan struktur dan perilaku pasar dipandang penting agar terjadi peningkatan daya saing produk melalui peningkatan efesiensi pemasaran produk sayuran.

\section{B. METODE PENELITIAN}

Penelitian dilakukan di Desa Kanreapia, Kecamatan Tinggimoncong, Kabupaten Gowa, Propinsi Sulawesi Selatan, pada bulan April hingga Juni 2019. Sampel petani produsen berjumlah 42 orang yang diambil secara acak (10\% dari populasi). Sampel pedagang diambil secara penunjukan langsung yakni; 5 orang pedagang pengumpul yang berdomisili di lokasi penelitian, 60 orang pedagang pengecer yang mewakili 3 pasar utama tradisional yaitu Pasar Sungguminasa Gowa, Pasar Terong, Pasar Sentral Makassar dan 4 pasar swalayan di Kota Makassar. Data dikumpulkan dengan penggunaan kuisioner. Analisis data dilakukan secara kuantitatif untuk menghitung margin pemasaran dan analisis kualitatif untuk mengetahui perilaku pasar, saluran pemasaran dan stuktur pasar.

\section{HASIL DAN PEMBAHASAN}

Distribusi merupakan salah satu aspek pemasaran yang menekankan bagaimana suatu produksi dapat sampai ke tangan konsumen. Proses pendistribusian dapat dikatakan efesien apabila mampu menyampaikan hasil produksi kepada konsumen dengan biaya terendah dan mampu mengadakan pembagian keuntungan dan adil dari keseluruhan harga yang dibayar konsumen kepada semua pihak yang ikut serta dalam kegiatan produksi dan distribusi. Pemilihan saluran pemasaran yang optimal berhubungan dengan faktor resiko, keuntungan, biaya tenaga kerja, preferensi gaya hidup dan volume penjualan (LeRoux et al, 2010).

Terdapat tiga pelaku pasar yang memegang peranan penting dalam pendistribusian sayuran di Desa Kanreapia. Ketiganya adalah petani/produsen sayuran, pedagang perantara dan konsumen. Petani adalah orang yang langsung berhubungan dengan proses produksi sayuran. Konsumen adalah pembeli terakhir produk sayuran dan pedagang perantara adalah pengusaha yang tidak langsung berhubungan dengan proses produksi melainkan hanya sebagai penyalur produksi sayuran.

Pedagang perantara yang terlibat langsung dalam distribusi sayuran yang berasal dari desa Kanreapia adalah :

a. Pedagang pengumpul yang merupakan lembaga perantara yang membeli sayuran langsung dari petani produsen untuk selanjutnya disalurkan kepada 
pedagang pengecer di pasar umum, pasar swalayan dan pedagang keliling.

b. Pedagang pengecer yang berfungsi sebagai lembaga yang langsung berhubungan dengan konsumen. Pedagang pengecer umumnya menjual sayuran dalam jumlah yang sedikit kepada para konsumen

Berdasarkan hasil kajian dan analisis terhadap tanggungjawab masing-masing lembaga pemasaran, diketahui bahwa sistem pemasaran sayuran yang banyak digunakan olehpetani di Desa Kanreapia adalah bersifat konvensional dengan bentuk kontraktual. Haji J, (2010) mengemukakan bahwa pelaksanaan kontrak didasarkan atas saling percaya dan bertujuan untuk mengurangi risiko pembayaran terutama yang disebabkan oleh kerusakan produk. Di dalam praktek perdagangan sayuran di desa Kanreapia, kendali keputusan dipegang oleh pedagang perantara yang terlihat dari kecenderungan perantara menghendaki tingkat keuntungan yang lebih tinggi, dan di lain pihak petani tidak memiliki posisi tawar yang kuat. Sistem kontraktual terjadi juga disebabkan petani kesulitan mengakses lembaga kredit formal sehingga banyak petani yang meminjam kepada para pedagang dan ketika panen, skema pembayaran memaksa petani ke dalam pengaturan perdagangan (Milagrosa, A., 2006). Di desa Kanreapia, dalam hal pelaksanaan kontraktual tidak banyak, yaitu hanya dilakukan oleh para pedagang antar pulau atau eceran (pada pasar swalayan). Sistem kontraktual biasanya lebih menjamin kontinuitas pemasaran, harga jual yang ditetapkan relatif stabil, tetapi tidak banyak menguntungkan petani produsen namun demikian petani berharap mendapatkan kepastian pasar bagi produknya dan tidak menyulitkan mereka sebab pedagang pengumpul yang datang untuk mengadakan transaksi jual beli.

Stuktur pasar sayuran yang terbentuk di desa Kanreapia dapat dikatakan mengarah pada pasar yang bersifat oligopsoni hal tersebut terjadi akibat kurangnya kompetisi di antara pedagang sebagai akibat dari jumlah pedagang yang terbatas, dan kalaupun jumlah pedagang yang terlibat cukup banyak tetapi sesungguhnya dalam kegiatannya para pedagang tersebut seringkali dikendalikan oleh beberapa pedagang tertentu. Kondisi pasar seperti ini tidak menguntungkan bagi petani karena harga yang diterima petani dikendali kan oleh pedagang. Pada kondisi tersebut petani cenderung menerima harga yang rendah akibat pedagang yang berusaha memaksimumkan keuntungannya.

Struktur pasar di tingkat Kabupaten /Kota, lebih mengarah pada pasar persaingan sempurna dan diferensiasi. Struktur pasar 
yang mendekati persaingan sempurna terjadi pada perdagangan komoditi petsai, cabai merah, bawang daun dan tomat. Sedangkan stuktur pasar diferensiasi terjadi pada komoditas kentang, kubis dan buncis. Komoditas kentang diklasifikasikan berdasarkan ukuran dengan kualifikasi A, B dan C. Kentang dengan kualitas A dijual melalui saluran pemasaran khusus seperti pasar-pasar swalayan dan kentang dengan kualitas B dan C dijual pada pasar-pasar tradisional (pasar umum). Komoditas kubis diklasifikasikan berdasarkan mutu. Mutu I memiliki warna kulit lebih licin,ukuran lebih besar dan bentuk yang bulat dan padat. Mutu II memiliki krop agak kusam bentuknya kurang bulat dan tidak padat. Kubis mutu I biasanya dijual dipasar swalayan. Komoditas petsai, tomat, bawang daun dan cabai merah dapat dikategorikan tidak terdiferensiasi walaupun dalam praktek terkadang pedagang pengumpul tetap melakukan klasifikasi namun tidak bersifat baku.

Saluran distribusi sayuran yang berasal dari desa Kanreapia dapat dilihat pada gambar 1 .

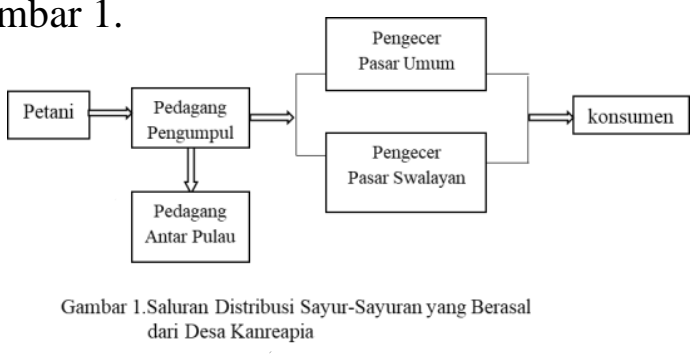

Pada Gambar 1. terlihat bahwa pendistribusian sayur-sayuran dari petani ke konsumen melalui sistem penyaluran tidak langsung karena terdapat dua pedagang perantara yaitu pedagang pengumpul dan pedagang pengecer. Lembaga pemasaran (petani dan pedagang perantara) mempunyai hubungan kegiatan yang terpisah, dengan demikian pemilikan keuntungan dari kegiatan pemasaran tersebut adalah terpisah antara petani dan pedagang perantara.

Para petani sayur-sayuran di desa Kanreapia pada dasarnya belum berorientasi pada usahatani dengan sistem agribisnis, hal ini dapat terlihat dari tidak adanya sarana pascapanen yang dimiliki petani sehingga mereka tidak mau mengambil resiko dalam hal penyimpanan produk. Mereka selalu ingin menjual produknya dengan segera. Hal inilah yang memungkinkan kehadiran pedagang perantara yang dalam hal ini pedagang pengumpul yang kemudian lebih dominan dalam hal penentuan harga jual di tingkat petani. Hal lain yang berkaitan dengan harga jual adalah kurangnya pengetahuan petani terhadap informasi pasar, ada kalanya harga di tingkat petani jauh lebih rendah dari harga jual sebenarnya, akibatnya bagian yang diterima oleh petani produsen dari harga yang dibayarkan oleh konsumen secara rata-rata lebih kecil dibandingkan yang diterima oleh pedagang perantara. Kenyataan ini dapat dilihat dari perolehan marjin pemasaran setiap lembaga yang 
berperan dalam pendistribusian sayursayuran yang berasal dari desa Kanreapia, yang menunjukkan ketidakefesienan pemasaran yang didefenisikan sebagai kegagalan petani untuk mencapai hasil pemasaran yang lebih baik yang tercermin dari indeks harga hasil yang rendah (Singho et al, 2014).

Marjin pemasaran terdiri atas keuntungan sebagai balas jasa atas kegiatan dilakukan dan biaya-biaya operasional pemasaran, yaitu biaya transportasi /pengangkutan, bongkar muat, biaya tarif pasar/retribusi dan biaya penyusutan. Banyaknya komponen marjin pemasaran ditentukan oleh rentang saluran pemasaran yang dilalui. Saluran pemasaran yang digunakan untuk menghitung nilai marjin dimulai dari tingkat petani, pengumpul, pengecer di pasar umum atau pasar swalayan. Analisis marjin pemasaran dilakukan untuk mengetahui besarnya tingkat marjin yang diperoleh masingmasing pelaku pasar dalam kegiatan pendistribusian sayuran. Hal tersebut bertujuan untuk mengetahui pelaku pasar mana yang menerima keuntungan paling besar dan seberapa besar keuntungan yang diterima petani. Biaya transportasi (pengangkutan) merupakan biaya yang dikeluarkan pedagang untuk mengangkut barang dagangan dari pasar penampungan ke pasar pengecer. Biaya bongkar muat adalah biaya yang dikeluarkan pedagang untuk menyewa tenaga kerja lepas guna mengantarkan sayuran dari kendaraan ke lokasi pembeli. Tarif restribusi pasar adalah biaya yang dikeluarkan pedagang pengecer untuk uang kebersihan dan sewa tempat setiap hari. Biaya Penyusutan merupakan sifat alami dari komoditas hortikultura, termasuk sayuran. Selain karena sifat sayursayuran yang mudah busuk, penyusutan terjadi sebagai akibat penanganan dan pengemasan yang kurang baik selama pengangkutan dari tempat penampungan ke pasar-pasar pengecer, serta susut berat dan adanya produk yang tidak laku terjual. Besar penyusutan berbeda-beda untuk tiap jenis komoditas sayuran.

Tabel 1. Rata-rata marjin, harga beli dan harga jual sayuran $(\mathrm{Rp} / \mathrm{Kg})$ pada saluran distribusi I

\begin{tabular}{|c|c|c|c|c|}
\hline \multirow[b]{2}{*}{$\begin{array}{l}\text { Jenis } \\
\text { Sayuran }\end{array}$} & \multirow[b]{2}{*}{$\begin{array}{l}\text { Lembaga } \\
\text { nasaran }\end{array}$} & \multicolumn{3}{|c|}{ Saluran Distribusi I } \\
\hline & & $\begin{array}{l}\text { Harga } \\
\text { Beli } \\
\text { (Rp) }\end{array}$ & $\begin{array}{l}\text { Marjin } \\
\text { (Rp) }\end{array}$ & $\begin{array}{l}\text { Harga } \\
\text { Jual } \\
\text { (Rp) }\end{array}$ \\
\hline \multirow{5}{*}{$\begin{array}{l}\text { Bawang } \\
\text { Daun }\end{array}$} & Petani & - & 2.500 & 3.000 \\
\hline & Pengumpul & 3.000 & 1.000 & 5.500 \\
\hline & P.P Umum & 5.500 & - & 6.500 \\
\hline & P.P Swalayan & - & - & - \\
\hline & Konsumen & 6.500 & - & - \\
\hline \multicolumn{2}{|c|}{ Total Marjin } & & 3.500 & \\
\hline & Petani & - & - & 9.000 \\
\hline & Pengumpul & 9.000 & 1.000 & 10.000 \\
\hline & P.P Umum & 10.000 & 2.000 & 12.000 \\
\hline \multirow[t]{2}{*}{ Buncis } & P.P Swalayan & - & - & - \\
\hline & Konsumen & 12.000 & - & - \\
\hline \multicolumn{2}{|c|}{ Total Marjin } & & 3.000 & \\
\hline \multirow{5}{*}{ Kubis } & Petani & - & - & 3.000 \\
\hline & Pengumpul & 3.000 & 1.000 & 4.000 \\
\hline & P.P Umum & 4.000 & 1.500 & 5.500 \\
\hline & P.P Swalayan & - & - & - \\
\hline & Konsumen & 5.500 & - & - \\
\hline \multicolumn{2}{|c|}{ Total Marjin } & & 2.500 & \\
\hline Kentang & Petani & - & - & 7.500 \\
\hline
\end{tabular}




\begin{tabular}{|c|c|c|c|c|}
\hline & Pengumpul & 7.500 & 2.000 & 9.500 \\
\hline & P.P Umum & 9.500 & 3.000 & 12.500 \\
\hline & P.P.Swalayan & - & - & - \\
\hline & Konsumen & 12.500 & - & - \\
\hline \multicolumn{2}{|c|}{ Total Marjin } & & 5.000 & \\
\hline & Petani & - & - & 3.000 \\
\hline & Pengumpul & 3.000 & 1.500 & 4.500 \\
\hline \multirow[t]{3}{*}{ Petsai } & P.P Umum & 4.500 & 5.500 & 10.000 \\
\hline & P.P Swalayan & - & - & - \\
\hline & Konsumen & 10.000 & - & _ \\
\hline \multicolumn{2}{|c|}{ Total Marjin } & & 7.000 & \\
\hline \multirow{5}{*}{ Tomat } & Petani & - & - & 7.000 \\
\hline & Pengumpul & 7.000 & 500 & 7.500 \\
\hline & P.P Umum & 7.500 & 2.500 & 10.000 \\
\hline & P.P Swalayan & - & - & - \\
\hline & Konsumen & 10.000 & - & - \\
\hline \multicolumn{2}{|c|}{ Total Marjin } & & 3.000 & \\
\hline \multirow{5}{*}{ Wortel } & Petani & 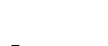 & & \\
\hline & Pengumpul & $\overline{4}-000$ & 1.000 & $\begin{array}{l}4.000 \\
5.000\end{array}$ \\
\hline & P.P Umum & 5.000 & 1.500 & 6.500 \\
\hline & P.P & & - & \\
\hline & $\begin{array}{l}\text { Swalayan } \\
\text { Konsumen }\end{array}$ & 6.500 & - & \\
\hline \multicolumn{2}{|c|}{ Total Mariin } & & 2.500 & \\
\hline
\end{tabular}

Sumber: Data Primer Setelah Diolah

Tabel 2. Rata-rata marjin, harga beli dan harga jual sayuran $(\mathrm{Rp} / \mathrm{Kg})$ pada saluran distribusi II

\begin{tabular}{|c|c|c|c|c|}
\hline \multirow{3}{*}{$\begin{array}{l}\text { Jenis } \\
\text { Sayuran }\end{array}$} & \multirow{3}{*}{$\begin{array}{l}\text { Lembaga } \\
\text { Pemasaran }\end{array}$} & \multicolumn{3}{|c|}{ Saluran Distribusi II } \\
\hline & & \multirow{2}{*}{$\begin{array}{l}\text { Harga } \\
\text { Beli (Rp) }\end{array}$} & \multirow{2}{*}{$\begin{array}{l}\text { Marjin } \\
\text { (Rp) }\end{array}$} & \multirow{2}{*}{$\begin{array}{l}\text { Harga } \\
\text { Jual } \\
\text { (Rp) }\end{array}$} \\
\hline & & & & \\
\hline \multirow{5}{*}{$\begin{array}{l}\text { Bawang } \\
\text { Daun }\end{array}$} & Petani & - & - & 3.000 \\
\hline & Pengumpul & 3.000 & 3.000 & 6.000 \\
\hline & P.P Umum & - & - & - \\
\hline & P.P Swalayan & 6.000 & 1.500 & 7.500 \\
\hline & Konsumen & 7.500 & - & - \\
\hline \multicolumn{2}{|c|}{ Total Marjin } & & 4.500 & \\
\hline & Petani & - & - & 9.000 \\
\hline & Pengumpul & 9.000 & 1.500 & 10.500 \\
\hline & P.P Umum & - & - & - \\
\hline \multirow[t]{2}{*}{ Buncis } & P.P Swalayan & 10.500 & 3,000 & 13.500 \\
\hline & Konsumen & 13.500 & - & - \\
\hline \multicolumn{2}{|c|}{ Total Marjin } & & 4.500 & \\
\hline & Petani & - & - & 3.000 \\
\hline \multirow{4}{*}{ Kubis } & Pengumpul & 3.000 & 2.000 & 5.500 \\
\hline & P.P Umum & - & - & - \\
\hline & P.P Swalayan & 5.500 & 1.500 & 7.000 \\
\hline & Konsumen & 7.000 & - & - \\
\hline \multicolumn{2}{|c|}{ Total Marjin } & & 3.500 & \\
\hline & Petani & - & - & 7.500 \\
\hline \multirow{4}{*}{ Kentang } & Pengumpul & 7.500 & 2.500 & 10.000 \\
\hline & P.P Umum & - & - & - \\
\hline & P.P.Swalayan & 10.000 & 4.000 & 14.000 \\
\hline & Konsumen & 14.000 & - & - \\
\hline \multicolumn{2}{|c|}{ Total Marjin } & & 6.500 & \\
\hline \multirow{5}{*}{ Petsai } & Petani & - & - & 3.000 \\
\hline & Pengumpul & 3.000 & 1.500 & 4.500 \\
\hline & P.P Umum & - & - & - \\
\hline & P.P Swalayan & 4.500 & 6.500 & 11.000 \\
\hline & Konsumen & 11.000 & - & - \\
\hline \multicolumn{2}{|c|}{ Total Marjin } & & 8.000 & \\
\hline
\end{tabular}

\begin{tabular}{|c|c|c|c|c|}
\hline & Petani & - & - & 7.000 \\
\hline & Pengumpul & 7.000 & 1.000 & 8.000 \\
\hline \multirow[t]{3}{*}{ Tomat } & P.P Umum & - & - & - \\
\hline & P.P Swalayan & 8.000 & 4.000 & 12.000 \\
\hline & Konsumen & 12.000 & - & - \\
\hline \multicolumn{2}{|c|}{ Total Marjin } & & 5.000 & \\
\hline \multirow{4}{*}{ Wortel } & Petani & - & - & 4.000 \\
\hline & $\begin{array}{l}\text { Pengumpul } \\
\text { P.P Umum }\end{array}$ & 4.000 & 1.500 & 6.500 \\
\hline & $\begin{array}{l}\text { P. P Swalayan } \\
\text { Konsumen }\end{array}$ & $\begin{array}{l}- \\
6.500\end{array}$ & & \\
\hline & Total Marjin & & 3.000 & \\
\hline
\end{tabular}

antara bentuk saluran I dan saluran II disebabkan karena adanya perbedaan biaya pemasaran yang dikeluarkan khususnya pada tingkat pedagang pengecer. Pengecer pada bentuk saluran II dalam hal ini adalah pengecer pasar swalayan sedangkan pada saluran I adalah pengecer pasar umum (tradisional). Mudah dipahami marjin pemasaran lebih besar pada bentuk saluran II mengingat bahwa pasar swalayan menetapkan harga jual lebih besar untuk semua jenis sayuran dibandingkan dengan pasar umum, sebab selain pasar swalayan mengeluarkan biaya pemasaran yang lebih besar seperti biaya-biaya operasional yang bertujuan untuk memberikan kenyamanan bagi konsumen, produk yang dijual memiliki kualitas yang lebih baik terutama pada komoditas yang terdiferensiasi seperti kentang dan kubis.

Jika dilihat dari perolehan marjin pada setiap tingkat saluran saluran, maka pada bentuk saluran distribusi I marjin terbesar diperoleh pedagang pengumpul. Untuk 
saluran distribusi II, marjin terbesar di peroleh pedagang pengecer untuk jenis sayuran bawang prei, buncis, kubis dan petsai, sedangkan untuk kentang dan tomat marjin terbesar diperoleh pedagang pengumpul.

Adapun bagian yang diterima tani dan pedagang perantara dari harga yang dibayarkan oleh konsumen secara persentase untuk setiap jenis sayuran pada bentuk saluran I dan II dapat dilihat pada

Tabel 3. Persentase yang diterima petani dan pedagang perantara berdasarkan harga yang dibayarkan oleh konsumen.

\begin{tabular}{llccc|}
\hline No & Jenis Sayuran & $\begin{array}{r}\text { Tingkat Harga } \\
(\mathrm{Rp} / \mathrm{Kg})\end{array}$ & \multicolumn{2}{c|}{$\begin{array}{r}\text { Bagian yang } \\
\text { diperoleh }(\%)\end{array}$} \\
\cline { 3 - 5 } & & Konsumen & Petani & Perantara \\
\hline 1 & Saluran I & & & \\
a. & Bawang Daun & 6.500 & 46,1 & 53,9 \\
& Buncis & & & \\
b. & Kubis & 12.000 & 75,0 & 25,0 \\
c. & Kentang & 5.500 & 54,5 & 45,5 \\
d. & Petsai & 12.500 & 60,0 & 40,0 \\
e. & Tomat & 10.000 & 30,0 & 70,0 \\
f. & Wortel & 10.000 & 70,0 & 30.0 \\
g. & & 6.500 & 61,5 & 38,5 \\
2. & Saluran II & & &
\end{tabular}

\begin{tabular}{llrrr} 
a. & Bawang Daun & 7.500 & 40,0 & 60.0 \\
& Buncis & & & \\
b. & Kubis & 13.500 & 66,0 & 34,0 \\
c. & Kentang & 7.000 & 42,8 & 57,2 \\
d. & Petsai & 14.000 & 53,6 & 46,4 \\
e. & Tomat & 11.000 & 27,3 & 72,7 \\
f. & Wortel & 12.000 & 58.3 & 41,7 \\
g. & & 8.000 & 50,0 & 50,0 \\
\hline
\end{tabular}

Sumber : Data Primer Setelah Diolah

Pada Tabel 2, terlihat bahwa pada bentuk saluran I yang melibatkan pasar tradisional secara rata-rata, bagian yang diterima petani dari harga yang dibayarkan oleh konsumen lebih tinggi $(56,7 \%)$ dibandingkan dengan bentuk saluran II yang melibatkan pasar moderen di perkotaan $(48,3 \%)$ padahal tingkat harga jual satuan pada bentuk saluran ke II lebih besar dibandingkan saluran I. Hal ini sejalan dengan temuan Otieno et al.,(2009) di Kenya bahwa ada perbedaan yang signifikan antara harga satuan penjualan sayuran di daerah pedesaan dan di daerah pekotaan. 


\section{KESIMPULAN DAN SARAN}

Kerjasama antar lembaga yan terlibat dalam pemasaran sayuran di Desa Kanreapia masih bersifat konvensional dan parsial dimana masing-masing lembaga tidak bertangungjawab terhadap lembaga lainnya dan kalaupun sistem kontrak dilaksanakan hanya sebatas perjanjian secara lisan yang dilandasi atas saling percaya.

Stuktur pasar sayuran yang terbentuk di desa Kanreapia dapat dikatakan mengarah pada pasar yang bersifat oligopsoni hal tersebut terjadi akibat kurangnya kompetisi di antara pedagang sebagai akibat dari jumlah pedagang yang terbatas. Struktur pasar di tingkat Kabupaten/Kota, lebih mengarah pada pasar persaingan sempurna dan terdiferensiasi. Struktur pasar yang mendekati persaingan sempurna terjadi pada perdagangan komoditi petsai, bawang daun dan tomat. Sedangkan stuktur pasar diferensiasi terjadi pada komoditas kentang, kubis dan buncis

Untuk beberapa jenis sayuran, baik pada bentuk saluran I maupun saluran II, bagian yang diterima petani dari harga yang dibayarkan oleh konsumen lebih rendah dari bagian yang diterima pedagang perantara. Hal ini mengindikasikan bahwa pola pemasaran yang diterapkan saat ini masih kurang efisien bagi petani produsen.

\section{DAFTAR PUSTAKA}

Arwanti, Sitti. 2016. Sistem Pemasaran Senyawa fenolik pada beberapa sayuran indigeneus dari indonesia. Seafast Center. Bogor.

Boeing H,A Bechthold,A Bub, S Ellinger, D Haller, A Kroke, E LeschikBonnet, MJ Muller, H Oberriter, M Schulze, P Stehle, B Watzl. 2012. Critical review: vegetables and fruit in the prevention of cronick diseases. Eur. J. Nutr 51: 637-663.

Darian J. C., Tucci L., 2013. Developing marketing strategies to increase vegetable consumption. Journal of Consumer Marketing 427-435 30 Maret 2013. ISSN 0736-3761. DOI 10.1108/JCM-02-2013-0468.

[FOA] Food and Agriculture Organisation. 2016. Food and agriculture data. http://fenix.fao.org/faostat/beta/en/\# home [ 10 september 2016].

Haji Jema, 2010. Te Entorcement of Traditional Vegetable Marketing Contracts in the Eastern and Central Parts of Ethiopia. Journal of African Economies, Vol. 19, number 5, pp. 768-792 doi:10.1093/jae/ejq012 online date 6 May 2010.

Irwan, B, 2003. Membangun Agribisnis Holtikultura Terintegrasi Dengan Basis Kawasan Pasar. Forum Peneliti Agro Ekonomi, Vol.21 No.1. Pusat Penelitian dan Pengembangan Sosial Ekonomi Pertanian 2006 dan Prospek 2007. Jakarta, 20 Desember 2006.

Irawan B, 2007. Fluktuasi Harga, Transmisi Harga dan Marjin Pemasaran Sayuran dan Buah, Jurnal Analisis kebijakan Pertanian Vol.5 No. 4. Desember 2007.

Kementerian Pertanian. 2010. Rencana Strategis Kementerian Pertanian 
2010-2014. Kementerian Pertanian, Jakarta.

LeRoux M. N., Schmit T. M., Roth M., Streeter D.H., 2010. Evaluating marketing channel options for smallscale fruit and vegetable producers. : Renewable Agriculture and Food Systems: 2591); 16-23. Doi:10.1017/S1742170509990275.

CambridgeUniversity Press 2010.

Milagnosa, A., 2006. Institutional Economic of vegetable production and marketing in northern Philippines: social capital, institution and governance: PhD.Thesis. Wageningen University Netherlands.

Otieno D. J., Omiti J., Nyanamba T., McCullough E., 2009. Market participation by vegetable farmers in Kenya: A comparison of rural and peri-urban areas. African Journal of Agricultural Research Vol. 4 (5), pp. 451-460, May 2009. ISSN 1991637X.http/www.academic journals.org/AJAR

Permana, Bintoro, Haris, 2006. Analisis jaringan Pemasaran Sayuran ( kasus Petani Kecil Ciwidey, bandung ). Jurnal MPI Vol 1 No.2. September 2006

Sayaka, B.I W. Rusastra, R Sajuti, Supiyati, W.K. Sejati, A. Agustian, J. Situmorang, Ashari, Y. Supriyatna, dan R. E, Manurung. 2008. Pengembangan Kelembagaan Pathnership Dalam Pemasaran Komuditas Pertanian. Laporan Hasil Penelitian. Pusat Analisis Sosial Ekonomi Dan Kebijakan Pertanian. Bogor.

Singbo A. G., Lansink A. O., Emvalomatis G., 2014. Estimating farmers'productive and marketing inefficiency: an application to vegetable producers in Benin: Springer DOI 10.1007/s11123-0140391-1. (16 April 2014). 